Supporting Information

\title{
Computer Simulations Reveal an Entirely Entropic Activation Barrier for the Chemical Step in a Designer Enzyme
}

\author{
Johan Åqvist* \\ Department of Cell and Molecular Biology, Uppsala University, Biomedical Center, \\ Box 596, SE-751 24 Uppsala, Sweden
}

*Corresponding author:

aqvist@xray.bmc.uu.se 

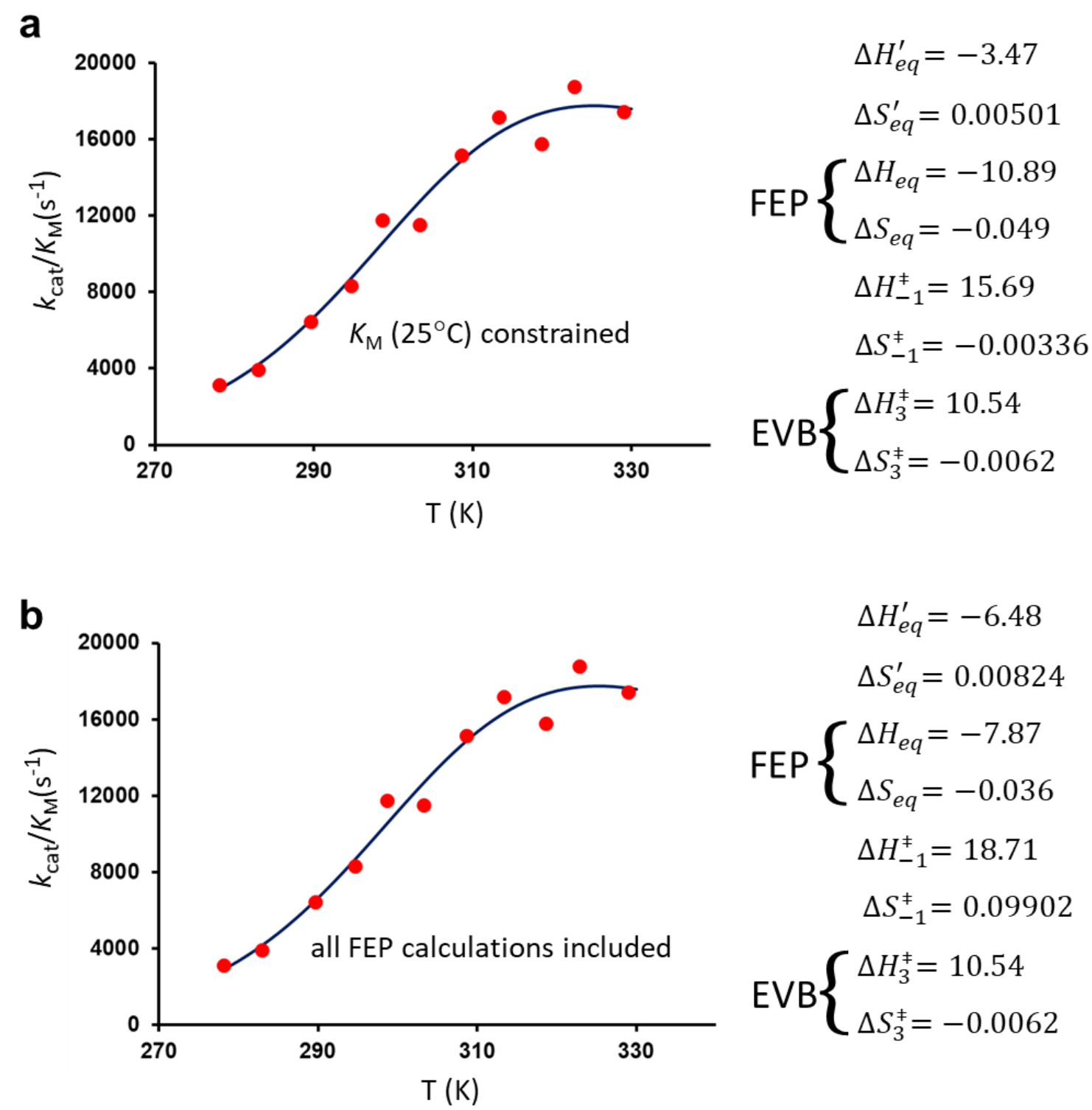

Figure S1. Fit of eq. (2) to the experimental values of $k_{\mathrm{cat}} / K_{\mathrm{M}}$ (red data points) where the thermodynamic parameters of $K_{e q}^{\prime}$ and $k_{-1}$ have been optimized, while those of $K_{e q}$ and $k_{3}$ are taken from the free energy simulations. Panel (a) shows the small effects of imposing a constraint on $K_{\mathrm{M}}$ at $25^{\circ} \mathrm{C}$ so that the experimental value of $710 \mu \mathrm{M}$ is exactly reproduced, $\Delta S_{e q}^{\prime}$ changes from 0.00376 to 0.00501 and $\Delta S_{-1}^{\ddagger}$ from -0.00210 to $-0.00336 \mathrm{kcal} / \mathrm{mol} / \mathrm{K}$ (see main text). Panel (b) shows the effects on the optimized parameters when all 30 replicates of the restraint release FEP simulations at each temperature are used to obtain the values of $\Delta H_{e q}$ and $\Delta S_{e q}$. 


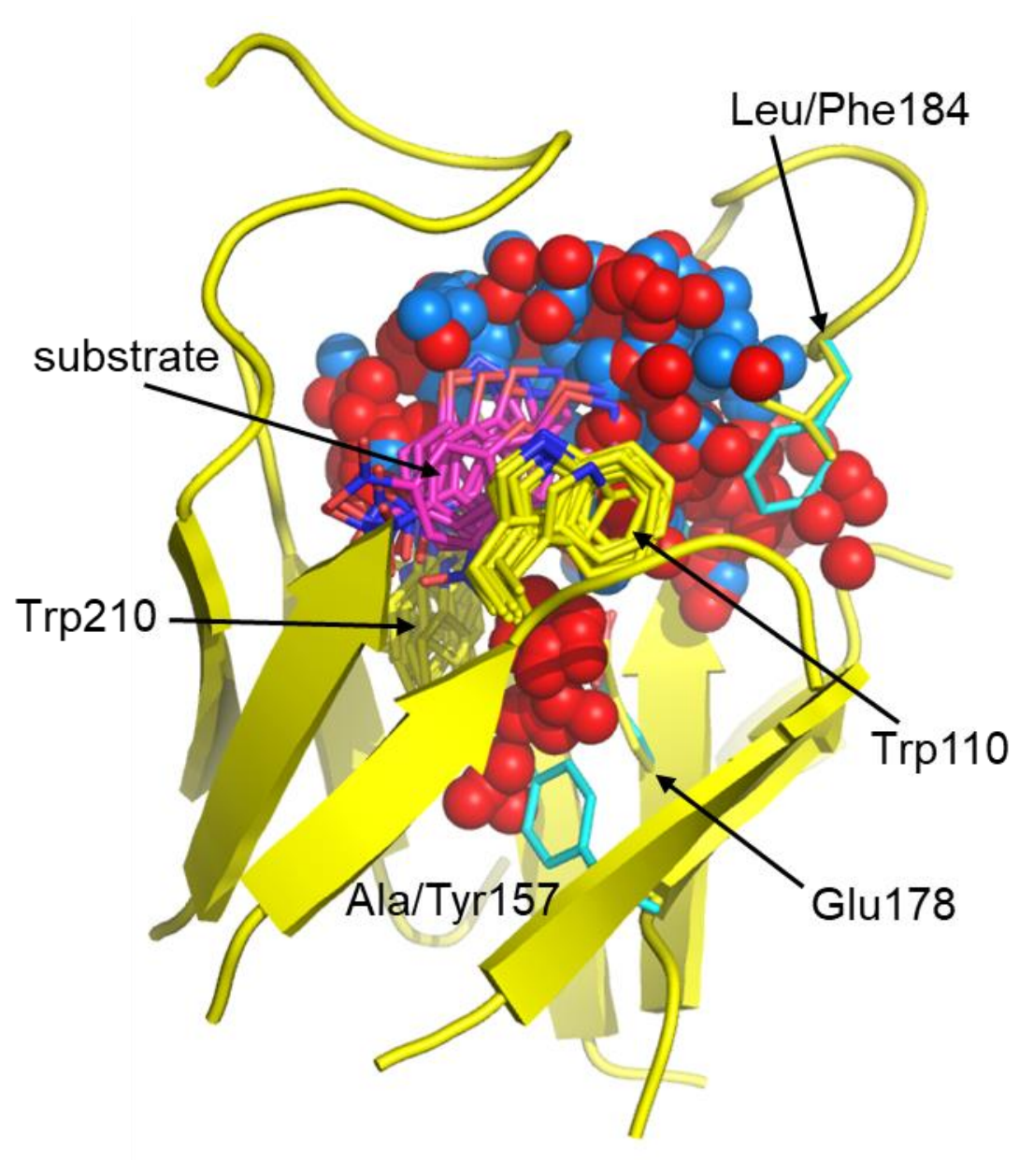

Figure S2. View of water cavities in the ES' state of the 1A53-2 enzyme. The crystallographic backbone structure of the enzyme is shown in yellow and the mutated positions A57Y and L184F are indicated with the 1A53-2.5 sidechains in cyan (the A180C mutation is hidden). Water positions from 10 restraint releaase simulations of each enzyme are overlayed with the 1A53-2 and 1A53-2.5 water oxygens shown as red and blue spheres, respectively. The conformation of the two tryptophans and the substrate from the 1A53-2 simulations are also overlayed and the position of the catalytic base (Glu178) is indicated. 